\title{
Evaluation of Anti-cancer and Pro-apoptotic Activities of Iranian Green Tea Extract Against A549, PC3, and MCF-7 Cancer Cell Lines
}

\author{
'Department of Biology, Faculty of Science, University of Guilan, Rasht, Iran \\ ${ }^{2}$ Department of Biology, Payame Noor University (PNU), Tehran, Iran \\ ${ }^{3}$ Department of Agriculture, Payame Noor University (PNU), Tehran, Iran
}

Fatemeh Safari ${ }^{*}{ }^{*}$, Masomeh Rabieepor ${ }^{2}$, Fatemeh Jamalomidi', Zahra Baghaeifar ${ }^{2}$, Leila Khodaei ${ }^{3}$

\section{*Correspondence to} Fatemeh Safari, Department of Biology, Faculty of Science, University of Guilan, Rasht, Iran. E-mail: fsafari@guilan.ac.ir

Received April 27, 2019 Accepted June 26, 2019 Published online September 30, 2019

\begin{abstract}
Introduction: Green tea contains active polyphenols including catechins. The goal of the current study was to evaluate anti-cancer effects of Iranian green tea extract (IGTE) on 3 human cancer cell lines including A549, PC3, and MCF-7.

Methods: First, Camellia sinensis was obtained from Lahijan, a city in the north of Iran and then IGTE was prepared. Next, catechins of IGTE were determined using high-performance liquid chromatography (HPLC). Finally, the cell viability of different cancer cells was evaluated by treatment with IGTE at concentration between 100 and $1000 \mu \mathrm{g} / \mathrm{mL}$ for 72 hours using MTT assay. Cell death of treated cancer cells was assessed by DAPI staining and RT-PCR method. Results: Our results demonstrated the potential anti-tumor activity of IGTE on MCF-7 cells $\left(\mathrm{IC}_{50}=\right.$ $400 \mu \mathrm{M})$, A549 cells $\left(\mathrm{IC}_{50}=500 \mu \mathrm{M}\right)$, and PC3 cells $\left(\mathrm{IC}_{50}=600 \mu \mathrm{M}\right)$, respectively. Chromatin damages within the nucleus of the treated cancer cells were shown. In addition, we found that IGTE induced apoptosis by up-regulation of Bax (a pro-apoptotic protein) and down-regulation of Bcl2 (an anti-apoptotic protein).

Conclusion: Herein, we showed that IGTE is a potent natural product with anti-tumor activity on breast, lung, and prostate cancer cells. The efficacy of current therapies against cancer is limited by a range of adverse effects, toxicity, and drug resistance; therefore, new therapeutic strategies and more effective agents, particularly with natural origin, are desired and green tea may be a potent candidate in the field of cancer therapy.

Keywords: Iranian green tea extract, HPLC, Cancer cell lines, Apoptosis
\end{abstract}

Please cite this article as follows: Safari F, Rabieepor M Jamalomidi F, Baghaeifar Z, Khodaei L. Evaluation of anti-cancer and pro-apoptotic activities of Iranian green tea extract against A549, PC3, and MCF-7 cancer cell lines. Int J Basic Sci Med. 2019;4(3):113118. doi:10.15171/ ijbms.2019.21.

\section{Introduction}

Cancer is one of the main causes of human deaths worldwide which is characterized by the abnormal growth of cells and abnormal cells spreading throughout the body. According to the World Health Organization (WHO), lung, breast, and prostate cancers are the most common types of cancers worldwide with the highest death rates. ${ }^{1}$ Resistance to anticancer drugs and side effects of drugs are major barriers to the success of cancer treatments. Moreover, the increase of various cancers has encouraged the researchers to discover new more effective drugs with the lowest side effects especially from natural products. Among natural products, plants may serve as potent chemotherapeutic agents with less toxicity to normal mammalian tissues and low cost. $^{2}$ Tea with high amounts of catechins has been used as a favorite and popular beverage in the world and is considered as a healthy drink with health benefits. All different types of tea are produced from the leaves of Camellia sinensis (Theaceae family). Different types of tea result in differences in tea processing.,

Green tea has been widely studied for its health benefits and potential effects. It has been reported to have anti carcinogenic ${ }^{5,6}$ and anti-cardiovascular, ${ }^{7}$ inhibition of inflammation. ${ }^{8,9}$ Moreover, it has antioxidant activity. ${ }^{10,11}$ These benefits result from the catechins in green tea. Green tea catechins (GTCs) are a type of

(C) 2019 The Author(s); Published by Zabol University of Medical Sciences. This is an open-access article distributed under the terms of the Creative Commons Attribution License (http://creativecommons.org/licenses/by/4.0), which permits unrestricted use, distribution, and reproduction in any medium, provided the original work is properly cited. 
green tea polyphenols (GTPs) that exist at high levels in green tea. The main GTCs are epigallocatechin-3-gallate (EGCG), epicatechin (EC), epigallocatechin (EGC), and epicatechin-3-gallate (ECG). ${ }^{12}$ Several epidemiological studies reported that green tea intake reduced the risk of human cancers. ${ }^{13,14}$ Recently, anti-cancer activity of IGTE on Caco- 2 colorectal cancer cell line was evaluated. ${ }^{15}$

In this study, the anti-cancer effects of Iranian Green Tea Extract (IGTE) on 3 different human cancer cell lines including human non-small-cell lung cancer A549 cells, human prostate cancer PC3 cells, and human breast cancer MCF-7 cells were investigated. Interestingly, our study is the first report focusing on green tea extract originated from Iran with potential dietary agents for cancer chemoprevention or chemotherapy against 3 common cancers in Iran including breast, lung, and prostate.

\section{Materials and Methods}

Sample Preparation and Extraction

The fresh leaves of related plants were collected in March 2018 from Lahijan, Guilan province, Iran. Camellia sinensis was recognized in the Department of Pharmacognosy, Tehran University of Medical Sciences and the herbarium was registered as THE-6561. The young leaves were shade dried at room temperature for two weeks. Plant extraction was performed as previously described and stored at $-20^{\circ} \mathrm{C} .{ }^{16}$

HPLC Analysis of Total Catechins in Iranian Green Tea Extract

The total catechin standard was obtained from Sigma (a gift from Dr. D. Bakhshi, University of Guilan, Iran; (+)-Catechin hydrate, C15H14O16, FW 290.3 and 98\% purity; Cas No: 88191-48-4). Standard was prepared at a concentration of $100 \mathrm{mg} / \mathrm{mL}$ diluted in methanol. The HPLC analysis was performed using a PLATIN blue system (Knauer, Berlin, Germany). HPLC system equipped with a C18 column $(5 \mu \mathrm{m}, 150 \mathrm{~mm} \times 4 \mathrm{~mm})$ was used for the separation of analytes. The HPLC measurement conditions included flow rate $(1 \mathrm{~mL} / \mathrm{min})$ and the wavelength $(270 \mathrm{~nm})$ at ambient temperature. UV-visible was used as detector in this procedure. The mobile phase for the gradient elution consisted of Solvent A, $10 \mathrm{mM}$ sodium phosphate $(\mathrm{pH} 2.6)$, and Solvent B, acetonitrile $(93: 7, \mathrm{v} / \mathrm{v})$. Both the extract and standard were injected (injection volume: $20 \mu \mathrm{L}$ ) into reverse phase column and identifications were carried out using comparison of retention times and UV spectra of the extract and standard. Each experiment was repeated at least 3 times and run in triplicate.

\section{Cell Lines, Cell Culture, and MTT Assay}

Human non-small-cell lung cancer A549 cells, human breast cancer MCF-7 cells, and human prostate cancer PC3 cells were grown in conditions that have been mentioned in our previous experiment. ${ }^{17}$

The cytotoxicity of GTE against cancer cell lines was measured by 3-(4,5-dimethylthiazol-2-yl)-2,5-diphenyl tetrazolium bromide or MTT) assay (MTT assay kit, Bio IDEA, CatNo:BI1017, Iran) according to our previous report. $^{17}$

\section{DAPI Staining Assay}

DAPI staining assay was used to determine chromatin changes in A549 cells treated with IGTE for 24 hours. DAPI was purchased from Sigma-Aldrich (USA). All images were taken by an inverted fluorescent microscope (Nikon Eclipse Ti-E). ${ }^{17}$

\section{RNA Extraction, cDNA Synthesis, and Real-time PCR}

Total RNA was extracted using $500 \mu \mathrm{L}$ of Trizol $^{\circledR}$ reagent according to the protocol provided by the manufacturer (Invitrogen Life Technologies, Carlsbad, CA, USA), and cDNA was synthesized using ReveretAid M-Mulv Reverse Transcriptase Kit (Thermo Fisher Scientific, MA, USA). Real-time RT-PCR was then performed to amplify cDNA using SYBR green dye universal master mix (Bioron $\mathrm{GmbH}$, Germany) and the primers (Pishgam Biotech Co. Tehran, Iran) for GAPDH, Bax and Bcl-2 for 40 cycles. Data represent averaged copy number normalized to the GAPDH housekeeping gene. Thermal conditions of the PCR consisted of primary denaturation at $94^{\circ} \mathrm{C}$ for 2 minutes, 45 cycles of denaturation at $94^{\circ} \mathrm{C}$ for 30 seconds, annealing at $59^{\circ} \mathrm{C}$ for 30 seconds, and amplification at $72^{\circ} \mathrm{C}$ for 30 seconds. All reactions were triplicated..$^{18}$

\section{Statistical Analysis}

Data was analyzed and presented using SPSS version 22.0 (Chicago, IL, USA) and graphs were generated using GraphPad Prism 7 software. The results were expressed as means \pm standard deviation (SD). Between-group comparisons were performed using independent sample $t$-test. $P$-value of less than 0.05 was considered statistically significant. ${ }^{18}$

\section{Results}

For further confirmation of composition, IGTE was also subjected to HPLC technique. HPLC chromatogram of authentic standards is shown in Figure 1A. The identification of bioactive constituents was done according to the retention time $\left(t_{R}\right)$ obtained from authentic standards under identical HPLC conditions. As shown in Figure 1B, a peak corresponding to catechins in IGTE was identified in the order of catechins (6-7 minutes). In this study, linear regression was used for the measurement of the content, and the assay showed excellent linearity between Y (peak area of the standard polyphenols) and $\mathrm{X}$ (concentration of the polyphenols) with the correlation coefficients (R2) in the range of 0.9996 and the quantitative data were analyzed. The quantitative data were analyzed using their related calibration curves. 


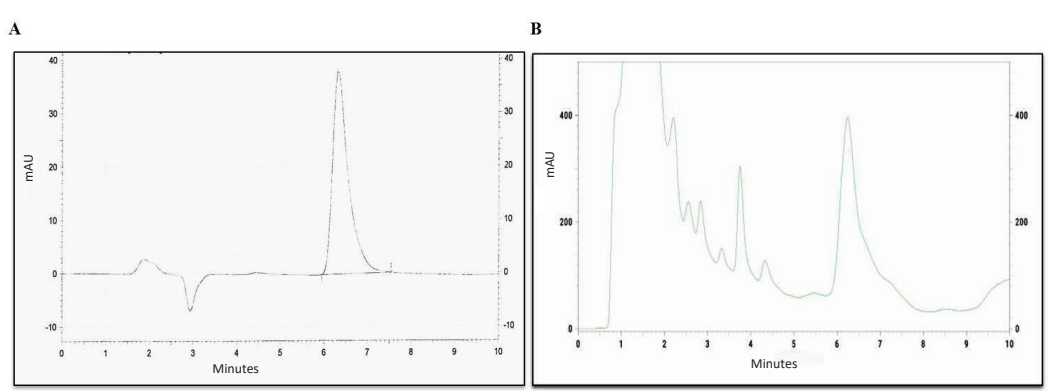

Figure 1. Typical HPLC chromatograms for the separation and analysis of (A) authentic standard of catechins and (B) catechins found in IGTE, as detected by absorbance at $270 \mathrm{~nm}$. Analysis of HPLC was performed as explained in the experimental section.

\section{Effect of IGTE on Viability of Cells}

The anti-cancer activities of IGTE against MCF-7, A549, and PC3 cells were evaluated by MTT assay. To do so, we cultured 3 cancer cell lines and then the cells were treated with different concentration of IGTE $(100-1000 \mu \mathrm{g} / \mathrm{mL})$ for 72 hours (Figure 2A, 2B, 2C). We used untreated cells and treated cells with Etoposide as negative and positive controls, respectively. IGTE showed different cytotoxicity against A549, MCF-7, and PC3 cell lines $\left(\mathrm{IC}_{50}=500 \mu \mathrm{M}\right.$ in A549, $400 \mu \mathrm{M}$ in MCF-7, and $600 \mu \mathrm{M}$ in PC3) (Table 1).

The Evaluation of the Changes in Cellular Nuclear Morphology Using DAPI Staining

To further determine the effect of IGTE on apoptotic cell death, the changes in cellular nuclear morphology of MCF-7, A549, and PC3 cell lines exposed to IGTE were examined by DAPI staining. As shown in Figure 3, the characteristic chromatin condensation and nuclear fragmentation were clearly shown in IGTE-treated cells. However, cells without IGTE treatment displayed potential health benefits with a large round nucleus and normal chromatin patterns.

Induction of Apoptosis in A549 Cells by Up-regulation of Bax and Down-regulation of $\mathrm{Bcl}-2$

In order to observe the effect of IGTE on the induction of apoptosis mediated by mitochondrial pathway, a quantitative real-time PCR was conducted on the desired target genes (Bax, Bcl-2) in A549 cells lines treated with IGTE for 72 hours at IC50 of $500 \mu \mathrm{M}$ (Table 2). As shown in Figure 4, IGTE induced apoptosis by increasing
mRNA expression of pro-apoptotic Bax and decreasing the expression of anti-apoptotic Bcl-2 in A549 cells lines. GAPDH was used as internal control. Our results indicated that the induction of apoptosis by IGTE in A549 might be attributed to the imbalance of the Bax and Bcl-2 expression.

\section{Discussion}

Green tea is a popular and favorite beverage worldwide. The main components of green tea are catechins, a family of polyphenols. EGCG is the major polyphenolic component of dried green tea extracts. In green tea leaves, EGCG accounts for at least $50 \%$ of the total catechin content. ${ }^{19}$ Many studies have been conducted administrating green tea extracts or pure EGCG and have shown that green tea consumption has beneficial effects on many human diseases. The involvement of several mechanisms in the protective effects of green tea extract and EGCG was demonstrated, including stimulation of anti-oxidant activity and activation of detoxification system, ${ }^{20,21}$ alteration of the cell cycle, ${ }^{22}$ suppression of mitogen-activated protein kinase (MAPK) and receptor protein kinase (RTKs) pathways, ${ }^{23,24}$ induction of apoptosis pathway mediating pro- and anti-apoptotic protein (Bax,

Table 1. IC50 Values of IGTE against Different Cells

\begin{tabular}{llll}
\hline Compounds & PC3 Cells & A549 Cells & MCF-7 Cells \\
\hline IGTE & $600 \pm 0.015$ & $500 \pm 0.017$ & $400 \pm 0.010$ \\
Etoposide & $40 \pm 0.046$ & $50 \pm 0.029$ & $60 \pm 0.009$ \\
\hline Note. Data are expressed as mean \pm SD of three independent experiments.
\end{tabular}

Note. Data are expressed as mean \pm SD of three independent experiments.
A

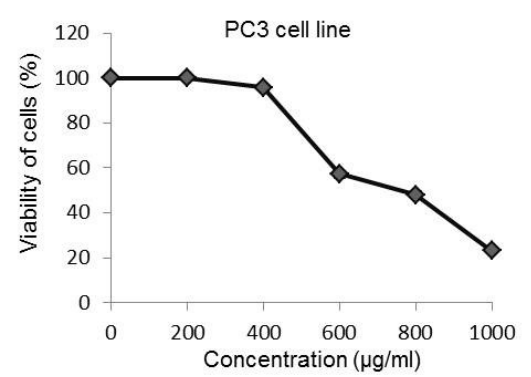

B

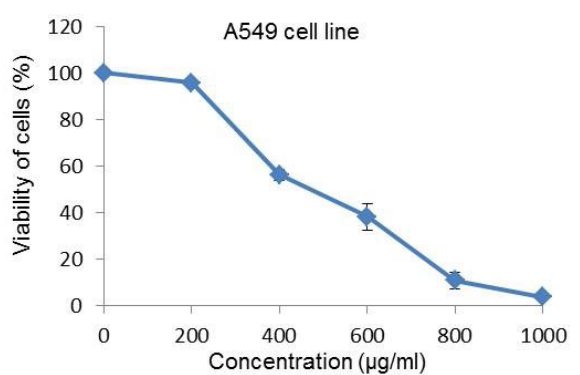

C

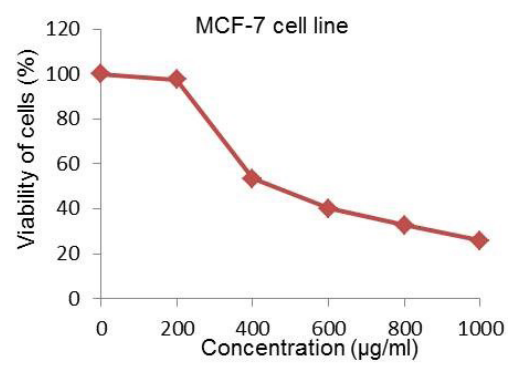

Figure 2. Effects of IGTE on cellular viability in different cancer cells including PC3, A549, and MCF-7 cells were shown (A, B, C). The cells were treated with medium at different concentrations of IGTE for 72 hours. 

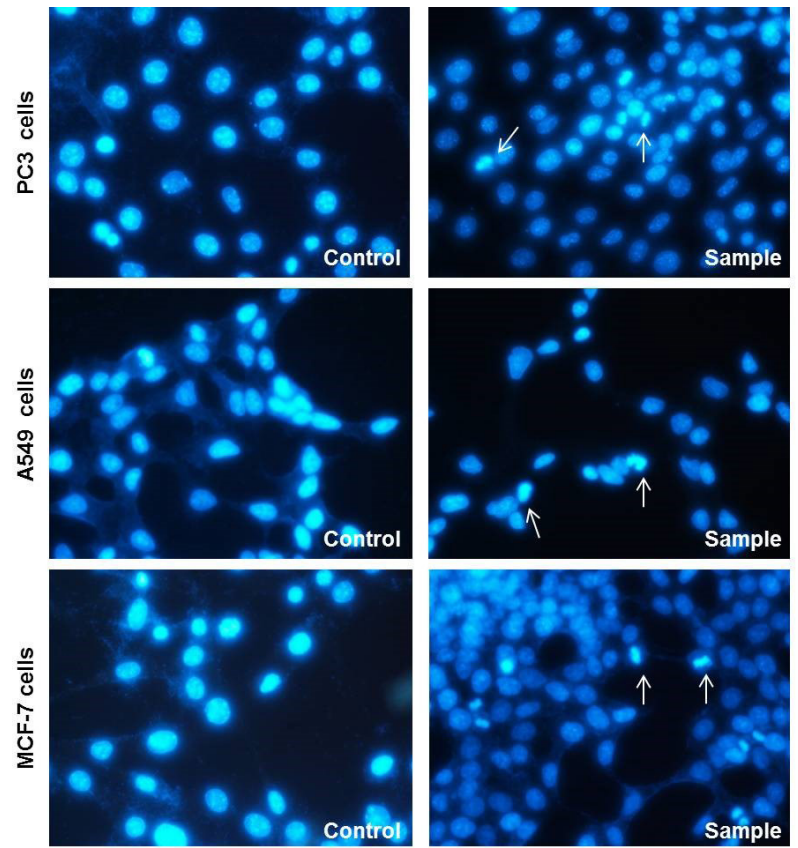

Figure 3. Inverted fluorescent microscopy images of chromatin damages occurred in the nucleus of treated cells with IGTE (as sample) and untreated cells (as control), which have been stained with DAPI in PC3, A549, and MCF-7 cancer cell lines. The experiments were done three times (original microscope magnification, 40X, Scale bar, $10 \mu \mathrm{m})$.

Table 2. List of Primers Used in RT-PCR Studies

\begin{tabular}{ll}
\hline Gene & Primer Sequence \\
\hline \multirow{2}{*}{ GAPDH } & For 5'-CAA GGT CAT CCA TGA CAA CTT TG-3' \\
& Rev 5'-GTC CAC CAC CCT GTT GCT GTA G-3' \\
\multirow{3}{*}{ Bax } & For 5'-GTC GCC CTT TTC TAC TTT GCC -3' \\
& Rev 5'-CTC CCG CCA CAA AGA TGG TCA-3' \\
BCl-2 & For 5'-CCC CTC GTC CAA GAA TGC AA-3' \\
& Rev 5'-TCT CCC GGT TAT CGT ACC CTG-3' \\
\hline
\end{tabular}

Bcl-2, Bcl-XL), and cell cycle regulator proteins (cyclins, $\mathrm{CDKs}){ }^{25}$

In this study, we showed anti-cancer activity of IGTE on different cancer cell lines including MCF-7, A549, and PC3. We demonstrated apoptotic effects of IGTE on human non-small-cell lung cancer A549 cells. IGTE caused a significant increase of Bax and decrease of Bcl2 mRNA, thereby indicating that intrinsic pathway of apoptosis was induced by IGTE in A549 cells.

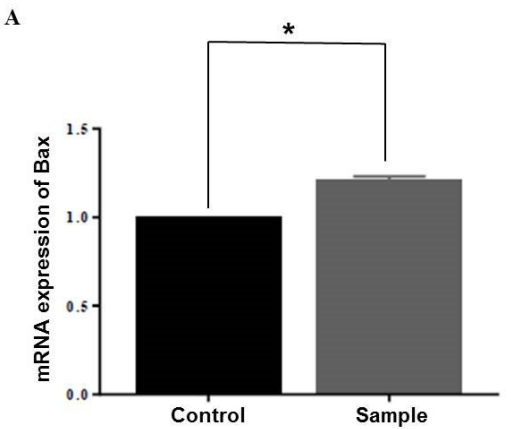

Interestingly, several in vivo studies have been done concerning the protective effects of green tea on lung cancer. ${ }^{26-28}$ However, some studies did not show the protective effects of green tea. ${ }^{29-31}$ Itseems that the protective effects of green tea depend on many factors including the dose of green tea consumption and genotype variation in populations. Lin et al studied genotype variations in lung cancer patients and reported a significantly higher tumor incidence in never tea drinkers. ${ }^{32}$

From in vitro studies, it was found that EGCG inhibited MMP-2 and -9 expressions in human lung cancer A549 cells. ${ }^{33}$ Additionally, an inhibitory effect of EGCG on the migration of bronchial tumor cells in 2D and 3D cell culture models has been shown. EGCG treatment also inhibited the expression of MMP-2 in both mRNA and protein levels and altered the intermediate filaments of vimentin. ${ }^{34}$ Moreover, green tea extraction induced expression of actin-binding protein, annexin-I at the

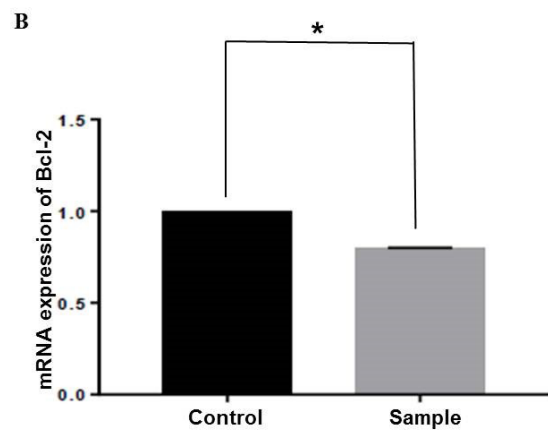

Figure 4. Relative expression of Bax mRNA (A) and relative expression of Bcl-2 mRNA (B) in A549 cells that were treated with IGTE (as sample) and untreated cells (as control) were shown. Data represent mean \pm SD of 3 independent experiments. ${ }^{*}$ indicates significance with a $P$ value $<0.05$. 
transcriptional level in A549 cells. The increased expression of annexin-I correlates with the stimulation of filamentous-actin (F-actin) polymerization, which in turn results in the increase of cell adhesion and decrease of cell motility in A549 cell line. ${ }^{35}$

\section{Conclusion}

In summary, the findings of the present study provide evidence for the protective effects of IGTE on lung cancer A549 cell. In vivo experiments will be required to confirm our results. These results may be helpful for interested researchers to design anti-cancer drugs.

\section{Ethical Approval}

Not applicable.

\section{Competing Interests}

There is no conflict of interests.

\section{References}

1. Bray F, Ferlay J, Soerjomataram I, Siegel RL, Torre LA, Jemal A. Global cancer statistics 2018: GLOBOCAN estimates of incidence and mortality worldwide for 36 cancers in 185 countries. CA Cancer J Clin. 2018;68(6):394-424. doi:10.3322/caac.21492

2. Jeong WS, Kim IW, Hu R, Kong AN. Modulatory properties of various natural chemopreventive agents on the activation of NF-kappaB signaling pathway. Pharm Res. 2004;21(4):661-670. doi:10.1023/ b:pham.0000022413.43212.cf

3. Graham HN. Green tea composition, consumption, and polyphenol chemistry. Prev Med. 1992;21(3):334-350. doi:10.1016/0091-7435(92)90041-f

4. Ho CT, Lin JK, Shahidi F. Tea and Tea Products; Nutraceutical Science and Technology Series. Vol 8. Boca Raton, FL, USA: CRC Press; 2009.

5. Butt MS, Ahmad RS, Sultan MT, Qayyum MM, Naz A. Green tea and anticancer perspectives: updates from last decade. Crit Rev Food Sci Nutr. 2015;55(6):792-805. doi:1 0.1080/10408398.2012.680205

6. Granja A, Pinheiro M, Reis S. Epigallocatechin gallate nanodelivery systems for cancer therapy. Nutrients. 2016;8(5). doi:10.3390/nu8050307

7. Nagao T, Hase T, Tokimitsu I. A green tea extract high in catechins reduces body fat and cardiovascular risks in humans. Obesity (Silver Spring). 2007;15(6):1473-1483. doi:10.1038/oby.2007.176

8. Liu D, Perkins JT, Hennig B. EGCG prevents PCB-126induced endothelial cell inflammation via epigenetic modifications of NF-kappaB target genes in human endothelial cells. J Nutr Biochem. 2016;28:164-170. doi:10.1016/j.jnutbio.2015.10.003

9. Behfarnia P, Aslani A, Jamshidian F, Noohi S. The efficacy of green tea chewing gum on gingival inflammation. J Dent (Shiraz). 2016;17(2):149-154.

10. Calo LA, Vertolli U, Davis PA, et al. Molecular biology based assessment of green tea effects on oxidative stress and cardiac remodelling in dialysis patients. Clin Nutr. 2014;33(3):437-442. doi:10.1016/j.clnu.2013.06.010
11. Vester H, Holzer N, Neumaier M, Lilianna S, Nüssler AK, Seeliger C. Green Tea Extract (GTE) improves differentiation in human osteoblasts during oxidative stress. J Inflamm (Lond). 2014;11:15. doi:10.1186/14769255-11-15

12. Anand J, Rai N, Kumar N, Gautam P. Green tea: a magical herb with miraculous outcomes. Int Res J Pharm. 2012;3(5):139-148.

13. Hwang JT, Ha J, Park IJ, et al. Apoptotic effect of EGCG in HT-29 colon cancer cells via AMPK signal pathway. Cancer Lett. 2007;247(1):115-121. doi:10.1016/j. canlet.2006.03.030

14. Shankar S, Ganapathy S, Hingorani SR, Srivastava RK. EGCG inhibits growth, invasion, angiogenesis and metastasis of pancreatic cancer. Front Biosci. 2008;13:440452. doi: $10.2741 / 2691$

15. Esghaei M, Ghaffari H, Rahimi Esboei B, Ebrahimi Tapeh Z, Bokharaei Salim F, Motevalian M. Evaluation of anticancer activity of Camellia sinensis in the Caco2 colorectal cancer cell line. Asian Pac J Cancer Prev. 2018;19(6):1697-1701. doi:10.22034/apjcp.2018.19.6.1697

16. Farhoosh R, Golmovahhed GA, Khodaparast MHH. Antioxidant activity of various extracts of old tea leaves and black tea wastes (Camellia sinensis L.). Food Chem. 2007;100(1):231-236. doi:10.1016/j.foodchem.2005.09.046

17. Bayat M, Safari F, Nasri S, Hosseini FS. A chemoselective synthesis and biological evaluation of novel benzo[g] thiazolo[3,2-a]quinolone derivatives. Monatsh Chem. 2019;150(4):703-710. doi:10.1007/s00706-018-2337-1

18. Safari F, Hosseini H, Bayat M, Ranjbar A. Synthesis and evaluation of antimicrobial activity, cytotoxic and proapoptotic effects of novel spiro-4H-pyran derivatives. RSC Adv. 2019;9(43):24843-24851. doi:10.1039/C9RA03196K

19. Khan N, Afaq F, Saleem M, Ahmad N, Mukhtar H. Targeting multiple signaling pathways by green tea polyphenol (-)-epigallocatechin-3-gallate. Cancer Res. 2006;66(5):2500-2505. doi:10.1158/0008-5472.can-053636

20. Thawonsuwan J, Kiron V, Satoh S, Panigrahi A, Verlhac V. Epigallocatechin-3-gallate (EGCG) affects the antioxidant and immune defense of the rainbow trout, Oncorhynchus mykiss. Fish Physiol Biochem. 2010;36(3):687-697. doi:10.1007/s10695-009-9344-4

21. Lambert JD, Elias RJ. The antioxidant and pro-oxidant activities of green tea polyphenols: a role in cancer prevention. Arch Biochem Biophys. 2010;501(1):65-72. doi:10.1016/j.abb.2010.06.013

22. Gupta S, Hastak K, Afaq F, Ahmad N, Mukhtar H. Essential role of caspases in epigallocatechin-3-gallate-mediated inhibition of nuclear factor kappa B and induction of apoptosis. Oncogene. 2004;23(14):2507-2522. doi:10.1038/ sj.onc. 1207353

23. Shimizu M, Adachi S, Masuda M, Kozawa O, Moriwaki $\mathrm{H}$. Cancer chemoprevention with green tea catechins by targeting receptor tyrosine kinases. Mol Nutr Food Res. 2011;55(6):832-843. doi:10.1002/mnfr.201000622

24. Singh BN, Shankar S, Srivastava RK. Green tea catechin, epigallocatechin-3-gallate (EGCG): mechanisms, perspectives and clinical applications. Biochem Pharmacol. 2011;82(12):1807-1821. doi:10.1016/j.bcp.2011.07.093 
25. Gupta S, Hussain T, Mukhtar H. Molecular pathway for (-)-epigallocatechin-3-gallate-induced cell cycle arrest and apoptosis of human prostate carcinoma cells. Arch Biochem Biophys. 2003;410(1):177-185. doi:10.1016/ s0003-9861(02)00668-9

26. Jin ZY, Han RQ, Zhang XF, et al. [The protective effects of green tea drinking and garlic intake on lung cancer, in a low cancer risk area of Jiangsu province, China]. Zhonghua Liu Xing Bing Xue Za Zhi. 2013;34(2):114-119.

27. Wang L, Zhang X, Liu J, Shen L, Li Z. Tea consumption and lung cancer risk: a meta-analysis of case-control and cohort studies. Nutrition. 2014;30(10):1122-1127. doi:10.1016/j. nut.2014.02.023

28. Wang Y, Yu X, Wu Y, Zhang D. Coffee and tea consumption and risk of lung cancer: a dose-response analysis of observational studies. Lung Cancer. 2012;78(2):169-170. doi:10.1016/j.lungcan.2012.08.009

29. Iso H, Kubota Y. Nutrition and disease in the Japan Collaborative Cohort Study for Evaluation of Cancer (JACC). Asian Pac J Cancer Prev. 2007;8 Suppl:35-80.

30. Li Q, Kakizaki M, Kuriyama S, et al. Green tea consumption and lung cancer risk: the Ohsaki study. Br J Cancer. 2008;99(7):1179-1184. doi:10.1038/sj.bjc.6604645
31. Arts IC, Hollman PC, Bueno De Mesquita HB, Feskens EJ, Kromhout D. Dietary catechins and epithelial cancer incidence: the Zutphen elderly study. Int J Cancer. 2001;92(2):298-302. doi:10.1002/10970215(200102)9999:9999<::aid-ijc1187>3.0.co;2-8

32. Lin $\mathrm{IH}, \mathrm{Ho} \mathrm{ML}$, Chen HY, et al. Smoking, green tea consumption, genetic polymorphisms in the insulinlike growth factors and lung cancer risk. PLoS One. 2012;7(2):e30951. doi:10.1371/journal.pone.0030951

33. Roomi MW, Monterrey JC, Kalinovsky T, Niedzwiecki A, Rath M. Modulation of MMP-2 and MMP-9 by cytokines, mitogens and inhibitors in lung cancer and malignant mesothelioma cell lines. Oncol Rep. 2009;22(6):1283-1291. doi:10.3892/or_00000566

34. Hazgui S, Bonnomet A, Nawrocki-Raby B, et al. Epigallocatechin-3-gallate (EGCG) inhibits the migratory behavior of tumor bronchial epithelial cells. Respir Res. 2008;9:33. doi:10.1186/1465-9921-9-33

35. Lu QY, Jin YS, Zhang ZF, et al. Green tea induces annexin-I expression in human lung adenocarcinoma A549 cells: involvement of annexin-I in actin remodeling. Lab Invest. 2007;87(5):456-465. doi:10.1038/labinvest.3700534 